\title{
Comparison of pre- versus post-incision administration of intraplantar indomethacin and MK886 in a rat model of postoperative pain
}

A.F. Gaspar and W.A. Prado
Departamento de Farmacologia, Faculdade de Medicina de Ribeirão Preto, Universidade de São Paulo, Ribeirão Preto, SP, Brasil

\section{Correspondence}

W.A. Prado

Departamento de Farmacologia

FMRP, USP

Av. Bandeirantes, 3900

14049-900 Ribeirão Preto, SP

Brasil

Fax: +55-16-3633-2301

E-mail: wadprado@fmrp.usp.br

Research supported by FAPESP.

A.F. Gaspar was the recipient of a

FAPESP fellowship (No. 02/08565-2).

Received December 12, 2006

Accepted May 3, 2007

\begin{abstract}
The amplification of pain long after the initial stimulus may be avoided if the treatment of pain is introduced before its initiation. However, conflicting evidence exists about the efficacy of such preemptive analgesia for the management of postoperative pain. This study compares the efficacy of intraplantar administration of indomethacin (a non-selective inhibitor of cyclooxygenase) and MK886 (an inhibitor of 5-lipoxygenase-activating protein), separately or in combination to produce preemptive analgesia in a model of surgical incisional pain in male Wistar rats. All incised rats (5 to 6 rats per group) had allodynia at 2, 6, and $24 \mathrm{~h}$ after surgery as evaluated using von Frey filaments. MK886, but not indomethacin (50 to $200 \mu \mathrm{g} /$ paw), reduced the allodynia when injected either $1 \mathrm{~h}$ before or $1 \mathrm{~h}$ after surgery. The effect of preoperative MK886 (160 $\mu \mathrm{g} / \mathrm{paw})$ against incisional allodynia had a magnitude apparently similar to that produced by postoperative MK886. Pre-, but not postoperative MK886 $(80 \mu \mathrm{g} / \mathrm{paw})$ reduced the allodynia but the effect was seen only at $6 \mathrm{~h}$ after surgery. In contrast, MK886 (40 $\mu \mathrm{g} / \mathrm{paw})$ intensified the allodynia observed $2 \mathrm{~h}$ after the incision either injected before or after surgery. MK886 or indomethacin alone did not provide preemptive analgesia in the model of incisional pain. In contrast, the combination of MK886 with indomethacin reduced the allodynia more effectively when used before than after surgery, thus fulfilling the criteria for preemptive analgesia. In conclusion, preoperative inhibition of the local generation of both prostaglandins and leukotrienes by surgical incision may be an alternative to provide preemptive analgesia.
\end{abstract}

Key words

- Preemptive analgesia

- Indomethacin

- MK886

- Postoperative pain

\section{Introduction}

Injury to peripheral tissues may produce prolonged pain, increased sensitivity to painful stimuli (hyperalgesia) and/or pain following innocuous stimulation (allodynia) (1).
These changes are usually accompanied by enlargement of the peripheral receptive field and increased excitability of spinal nociceptive cells to peripheral stimulation (2). A current hypothesis states that excitatory amino acids activating NMDA receptors in 
the spinal cord produce excessive cell depolarization that contributes to increased pain sensation (3). According to this hypothesis, the amplification of pain long after the initial stimulus may be avoided if the treatment of pain is introduced before its initiation (4). Some studies have reported the efficacy of such "preemptive analgesia" in laboratory animals following pre-surgical administration of opioids or of a local anesthetic (5-7). However, a local anesthetic before or soon after the end of surgery did not change the intensity of pain produced by herniorrhaphy (8) or cholecystectomy (9). Also, differences in the post-surgical pain were not detected in patients submitted to caudal or epidural block, or treated with systemic administration of opioids before or after surgery (10). The reasons for these conflicting results include the intra-operative administration of opioids as part of the general anesthesia procedures. Alternatively, pain perhaps depends more on the post-surgical peripheral inflammation than on the central sensitization developed during surgery $(11,12)$.

Intraperitoneal ketoprofen, but not morphine, dipyrone, diclofenac, or tenoxicam exhibits preemptive analgesic efficacy in a model of postoperative pain in rats (13). Ketoprofen differs from other non-steroidal antinflammatory drugs because, in addition to inhibiting cyclooxygenase, it also inhibits the 5-lipoxygenase-activating protein, thus preventing the generation of both prostaglandins and leukotrienes (14). Leukotrienes produce hyperalgesia in animals $(15,16)$ and human beings (17), and seem to play an important role in the maintenance of a longlasting nociceptive response (18). 5-Lipoxygenase inhibitors such as L-615,919 or ZM 230487 inhibit the hyperalgesia induced by platelet-activating factor (19) or nerve growth factor (20), respectively.

The present study compares the efficacy of local administration of indomethacin, a non-selective inhibitor of cyclooxygenase, to MK886, an inhibitor of the 5-lipoxyge- nase-activating protein (21), administered separately or in combination, in producing preemptive analgesia in a model of postoperative pain in rats.

\section{Material and Methods}

\section{Subjects and surgery}

The experiments were conducted on male Wistar rats (140-160 g) housed two to a cage with free access to food and water and maintained at an average ambient temperature of $24^{\circ} \mathrm{C}$ with a 12-h light-dark cycle before and after surgery. The proposals of the Committee for Research and Ethics Issue of IASP (22) were followed throughout the experiments.

Each animal was anesthetized with $2 \%$ halothane via a nose cone. Antisepsis of the plantar aspect of the right hind paw was made with a $10 \%$ povidone-iodine solution as described elsewhere (23). A 1-cm longitudinal incision was made with a surgical blade through the skin and fascia of the plantar region, starting $0.5 \mathrm{~cm}$ from the proximal edge of the heel. The plantaris muscle was elevated, but its origin and insertion were left intact. After hemostasis, the skin was apposed with two single sutures of 5-0 nylon, and the animal was allowed to recover in the home cage for a period of at least $1 \mathrm{~h}$.

\section{Algesimetric test}

Mechanical threshold was measured with flexible nylon Semmes-Weinstein von Frey filaments (Stoelting, Wood Dale, IL, USA). Rats were placed in an elevated clear plastic cage with a nylon mesh bottom, which allowed easy access to the paw plantar surface. Before the test procedures, the animals remained in the cage for approximately 15 min to allow behavioral accommodation. The area tested was 1-2 $\mathrm{mm}$ adjacent to the wound near the medial heel of the right hind 
paw and the mechanical thresholds were determined 2, 6, and $24 \mathrm{~h}$ after surgery. The paw was touched with one of a series of von Frey filaments with logarithmically incremental stiffness ( 0.69 to $28.84 \mathrm{~g}$, lower and upper limit of the test, respectively). Each filament was applied from underneath the nylon mesh floor through the mesh, vertically to the plantar surface with sufficient force to bend the filament a little. A single trial consisted of 6 applications of a particular filament, applied once every 3-4 s. Testing was initiated with the 3.63-g filament in the middle of the series. A response was defined as a withdrawal of the stimulated paw. In the absence of a response to a particular filament, the next stronger filament was used; in the case of a response, the next weaker filament was applied. The up-down method was used to record the thresholds (24).

\section{Drugs}

Indomethacin and MK886 were from Sigma-Aldrich Co. (St. Louis, MO, USA) and Tocris Cookson Inc. (Ellisville, MO, USA), respectively. Indomethacin, alone or in combination, was diluted in $50 \mu \mathrm{L}$ Tris $(0.1 \mathrm{M})$ buffer, MK886 was diluted in $50 \mu \mathrm{L}$ saline, and administered by the intraplantar route 1 $\mathrm{h}$ before, or $1 \mathrm{~h}$ after surgery. All injections were made using a 30-gauge needle coupled to a $1.0-\mathrm{mL}$ syringe. All doses in the text refer to the salt.

\section{Statistical analysis}

Data are reported as median and interquartile range against time after surgery. The experimental groups were compared by the non-parametric Friedman and KruskalWallis tests. Multiple comparisons after the Kruskal-Wallis test were performed using a two-tailed Mann-Whitney test. The level of significance was set at $\mathrm{P}<0.05$.

\section{Results}

\section{Changes in the incision pain induced by indomethacin}

Before the incision no rat responded to any filament in the series, but Tris-treated rats (control) had the mechanical threshold significantly reduced for up to $24 \mathrm{~h}$ after the incision. Rats treated with intraplantar indomethacin $(200 \mu \mathrm{g} / 50 \mu \mathrm{L}) 1 \mathrm{~h}$ before surgery had mechanical thresholds significantly higher than control at $24 \mathrm{~h}$ after the incision. The thresholds did not differ significantly from control at the remaining times of observation following indomethacin $(200 \mu \mathrm{g} / 50$ $\mu \mathrm{L}$ ) or throughout the period of observation in rats treated with smaller doses (50 or 100 $\mu \mathrm{g} / 50 \mu \mathrm{L}$ ) of indomethacin (Figure 1A). The data in Figure 1A differ significantly regarding treatments at time $24 \mathrm{~h}$ only (KruskalWallis test: $\chi^{2}{ }_{3}<6.0(\mathrm{P}>0.05)$ for $\mathrm{t}=2$ and $6 \mathrm{~h}$, and $\chi^{2}{ }_{3}=9.07(\mathrm{P}=0.028)$ for $\left.\mathrm{t}=24 \mathrm{~h}\right)$, but did not differ regarding time of observation (Friedman test: $\chi^{2}{ }_{24}=5.02 ; \mathrm{P}=0.08$ ).

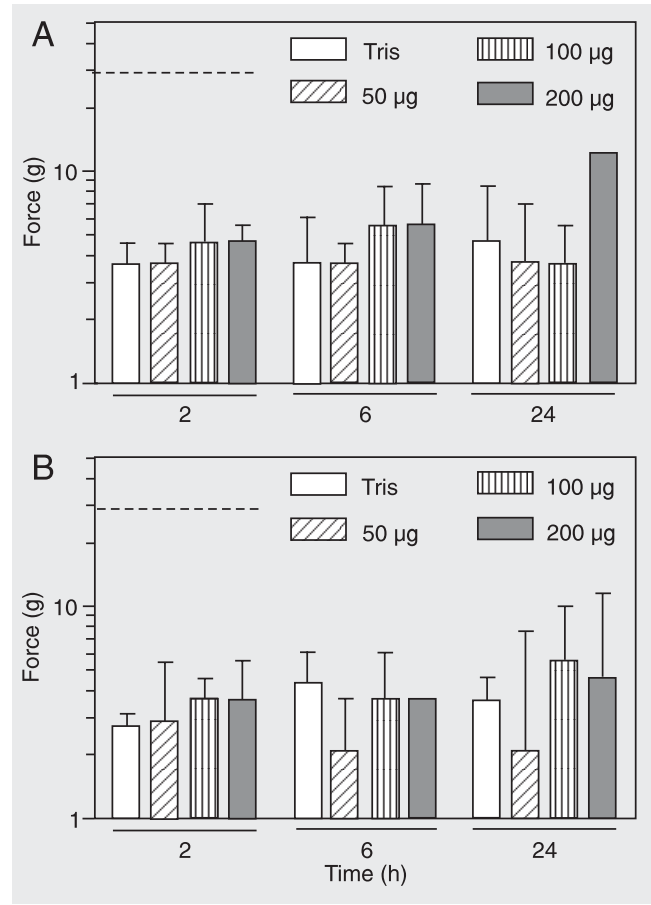

Figure 1. Changes produced by indomethacin in the post-incisional paw withdrawal thresholds in response to mechanical stimuli in rats. Indomethacin was administered by the intraplantar route $1 \mathrm{~h}$ before $(\mathrm{A})$ or $1 \mathrm{~h}$ after (B) surgery. Time after the incision is indicated as hours. The upper limit of the test $(28.84 \mathrm{~g})$ is indicated by a dotted line. Bars are the median and interquartile range of 5 to 6 rats per group. ${ }^{*} P$ $<0.05$ compared to control (Tris) at the respective time after the incision (Friedman and KruskalWallis tests followed by a twotailed Mann-Whitney test). 
Figure 2. Changes produced by MK886 in the post-incisional paw withdrawal thresholds in response to mechanical stimuli in rats. MK886 was administered by the intraplantar route $1 \mathrm{~h}$ before $(A)$ or $1 \mathrm{~h}$ after (B) surgery. Time after the incision is indicated as hours. The upper limit and bars are as in Figure 1. ${ }^{*} \mathrm{P}<$ 0.05 compared to control (saline) at the respective time after the incision (Friedman and KruskalWallis tests followed by a twotailed Mann-Whitney test).

Figure 3. Changes produced by the combination of indomethacin with MK886 in the post-incisional paw withdrawal thresholds in response to mechanical stimuli in rats. Indomethacin (Indo) and MK886 (MK) were administered by the intraplantar route $1 \mathrm{~h}$ before $(A)$ or $1 \mathrm{~h}$ after $(B)$ surgery at the doses of 50 and $40 \mu \mathrm{g}$, respectively (striped bars) or 200 and $160 \mu \mathrm{g}$, respectively (gray bars). Time after the incision is indicated as hours. The upper limit and bars are as in Figure 1. ${ }^{*} \mathrm{P}<0.05$ compared to control (Tris; white bars) at the respective time after the incision (Friedman and Kruskal-Wallis tests followed by a two-tailed MannWhitney test).
The post-surgical injection of indomethacin (50 to $200 \mu \mathrm{g} / 50 \mu \mathrm{L})$ did not significantly change the mechanical threshold throughout the period of observation (Figure 1B). The data in Figure 1B were significantly
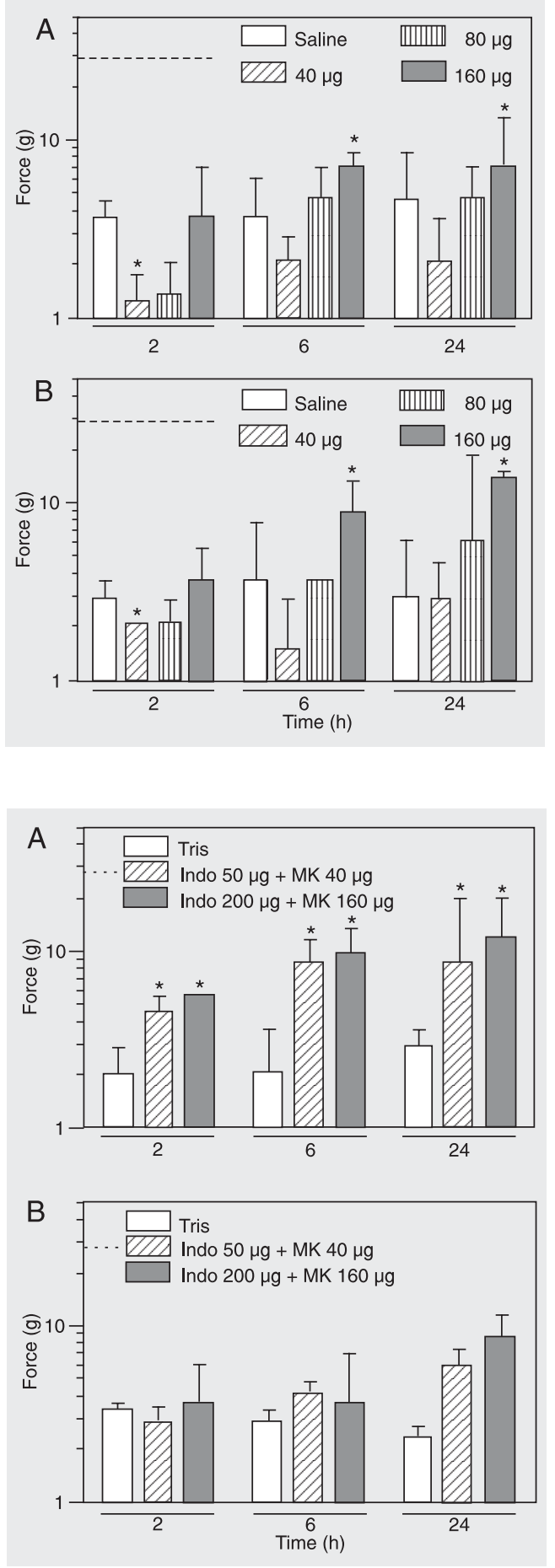

different regarding treatments only at $6 \mathrm{~h}$ (Kruskal-Wallis test: $\chi_{3}{ }_{3}=9.75 ; \mathrm{P}=0.02$ ) and time of observation (Friedman test: $\chi^{2}{ }_{24}$ $=27.58 ; \mathrm{P}<0.0001)$.

\section{Changes in the incision pain induced by MK886}

The intraplantar injection of MK886 (40, 80 , or $160 \mu \mathrm{g} / 50 \mu \mathrm{L}$ ) performed $1 \mathrm{~h}$ before surgery produced significant changes in the mechanical threshold (Figure 2A). The low dose of MK886 further reduced the mechanical threshold throughout the period of observation, but the effect was significantly different from control (saline) only at $2 \mathrm{~h}$ after the incision. The mid-dose of MK886 also reduced the mechanical threshold at $2 \mathrm{~h}$ after the incision, but the effect was not significantly different from control. In contrast, the mechanical threshold recorded at 6 and $24 \mathrm{~h}$ was dose-dependently increased by the mid-dose of MK866, but the effects were not significantly different from control. Animals treated with the high-dose of MK886 had higher thresholds than control throughout the period of observation, but the differences were significant only at 6 and $24 \mathrm{~h}$ after surgery. The data in Figure 2A differ significantly regarding treatments (KruskalWallis test: $\chi^{2}{ }_{3}=8.17(\mathrm{P}=0.04), \chi^{2}{ }_{3}=11.7$ $(\mathrm{P}=0.008)$, and $\chi^{2}{ }_{3}=11.6(\mathrm{P}=0.008)$, for $\mathrm{t}$ $=2,6$, and $24 \mathrm{~h}$, respectively), and time of observation (Friedman test: $\chi^{2}{ }_{23}=27.4 ; \mathrm{P}<$ 0.0001).

The post-incision administration of MK886 also produced dose-dependent and significant changes in the incision pain (Figure 2B). The lower doses of MK886 reduced the mechanical threshold throughout the period of observation, but the effect was significantly different from the control at $2 \mathrm{~h}$ after the incision only. The mid-dose of MK886 produced different effects depending on the time of observation: the threshold was not significantly reduced at $2 \mathrm{~h}$, did not differ from control at $6 \mathrm{~h}$, and was not sig- 
nificantly higher than control at $24 \mathrm{~h}$ after the incision. In contrast, the high dose of MK866 induced an antinociceptive effect that was significantly different from control at 6 and $24 \mathrm{~h}$ after the incision. The data in Figure 2B differ significantly regarding treatments at 6 and $24 \mathrm{~h}$ (Kruskal-Wallis test: $\chi^{2}{ }_{3}$ $=11.8(\mathrm{P}=0.008)$ and $\chi_{3}{ }_{3}=9.8(\mathrm{P}=0.02)$, respectively) and time of observation (Friedman test: $\chi_{24}^{2}=14 ; \mathrm{P}=0.0009$ ).

The effects produced by each dose of MK886 when injected before the incision were not significantly different from the effects produced by the same doses injected after the incision (Mann-Whitney test: $\mathrm{U} \geq$ $8 ; \mathrm{P} \geq 0.09$ ).

\section{Changes in incision pain induced by the combination of indomethacin with MK886}

The intraplantar administration of indomethacin combined with MK886 at low (50 $\mu \mathrm{g}$ and $40 \mu \mathrm{g} / 50 \mu \mathrm{L}$, respectively) or high doses $(200 \mu \mathrm{g}$ and $160 \mu \mathrm{g} / 50 \mu \mathrm{L}$, respectively) $1 \mathrm{~h}$ before the incision produced a significant increase in the mechanical threshold throughout the period of observation (Figure $3 \mathrm{~A}$ ). The mechanical threshold of rats treated with the combination was significantly higher than of control (Tris) rats throughout the period of observation. The effect obtained after the combination of small doses was less intense than that produced by the combination of high doses, but the difference was not significant. The data in Figure $3 \mathrm{~A}$ differ significantly regarding treatments at all times (Kruskal-Wallis test: $\chi^{2}{ }_{2}=$ $11.6(\mathrm{P}=0.005), \chi^{2}{ }_{2}=11.4(\mathrm{P}=0.003)$, and $\chi^{2}{ }_{2}=11.4(\mathrm{P}=0.003)$ at 2,6 , and $24 \mathrm{~h}$, respectively) and time of observation (Friedman test: $\left.\chi^{2}{ }_{18}=31 ; P<0.0001\right)$. In contrast, post-surgical administration of the same combinations produced few changes in the mechanical threshold. Thresholds higher than control were obtained only at $24 \mathrm{~h}$ after surgery in the group of rats treated with the combination of high doses of each drug (Fig- ure 3B). The data in Figure 3B did not differ significantly regarding treatments at all times (Kruskal-Wallis test: $\chi^{2}{ }_{2}=73.1(\mathrm{P}=0.695)$, $\chi_{2}^{2}=2.18(\mathrm{P}=0.33)$, and $\chi^{2}{ }_{2}=5.73(\mathrm{P}=$ 0.056 ) at 2,6 , and $24 \mathrm{~h}$, respectively), but differ significantly regarding time of observation (Friedman test: $\chi^{2}{ }_{17}=11.4 ; \mathrm{P}=$ 0.0033).

The effects produced by each combination when injected before the incision were significantly stronger than the effects produced by the same combinations injected after the incision at all times of observation (Mann-Whitney test: $\mathrm{U} \leq 4 ; \mathrm{P}<0.03$ ).

In separate groups of rats, saline (control) or indomethacin combined with MK886 (200 $\mu \mathrm{g}$ and $160 \mu \mathrm{g} / 50 \mu \mathrm{L}$, respectively) was injected into the hind paw contralateral to the incised paw $1 \mathrm{~h}$ before or $1 \mathrm{~h}$ after surgery. In these cases, the threshold in the incised paw did not differ significantly from control throughout the period of observation (data not shown in Figures).

The control groups of the different experiments did not differ significantly during the period of observation (Kruskal-Wallis test: $\left.\chi^{2} \leq 4.02 ; \mathrm{P} \geq 0.13\right)$.

\section{Discussion}

No rat in this study responded to the highest force applied to the hind paw skin before the incision but they all responded to lower pressures after the incision. Therefore, the incision produces mechanical allodynia, i.e., pain from stimuli that are not normally painful. A hind paw incision evokes spontaneous activity of $\mathrm{A} \delta$ - and $\mathrm{C}$-fibers (25), increases the peripheral receptive field (26) and activates and sensitizes dorsal horn cells in the spinal cord (27). This surgical incision-induced central sensitization can therefore be changed by preemptive analgesia.

The present study shows that the intraplantar injection of MK886, but not indomethacin, changed the mechanical allodynia when injected either $1 \mathrm{~h}$ before or $1 \mathrm{~h}$ after 
surgery. The efficacy of indomethacin (3 to $30 \mathrm{mg} / \mathrm{kg}$ ) against mechanical allodynia induced by a surgical incision in rats has already been demonstrated following oral administration $(28,29)$. Therefore, the lack of efficacy of indomethacin is probably due to the low doses used in this study. The intensity of allodynia was reduced by a similar magnitude by MK886 (160 $\mu \mathrm{g} / \mathrm{paw})$ injected either pre- or postoperatively. Pre- or postoperative MK886 (80 $\mu \mathrm{g} / \mathrm{paw})$ produced nonsignificant changes of allodynia throughout the period of observation. In contrast, MK886 (40 $\mu \mathrm{g} / \mathrm{paw})$ injected either before or after surgery increased the mechanical allodynia at $2 \mathrm{~h}$ after the incision, but did not change significantly the mechanical threshold during the remaining times of observation.

Inhibitors of 5-lipoxygenase-activating protein are only effective in intact cells (30). A surgical incision certainly produces cell disruption, thus leading to immediate local arachidonic acid release that could in turn reduce the local efficacy of 5-lipoxygenaseactivating protein inhibitors (31). In fact, the pronociceptive effect of the low-dose of MK886 was no longer observed when the drug was given with indomethacin.

The current notion about preemptive analgesia admits that the preoperative administration of an analgesic must provide a more effective reduction of pain than an analgesic administered postoperatively (32). Therefore, MK886 or indomethacin alone does not provide preemptive analgesia in the model of incision pain. Pre- or postoperative injection of MK886 combined with indomethacin significantly reduced the mechanical allodynia. However, the combination was significantly more effective when used before than after surgery, thus fulfilling the criteria for preemptive analgesia.

Intraplantar injection was performed here in a volume of $50 \mu \mathrm{L}$ to minimize the probability that the injected drug would leak out of the incised skin. Although still possible with this volume, we would expect that the chance of leakage would be the same in all experiments conducted in this study. Indomethacin alone was ineffective and MK886 was less effective alone than in combination with indomethacin. Therefore, the lack of efficacy of indomethacin or the low efficacy of MK886 when given alone is unlikely to be due to drug leakage out of the incised skin. The efficacy of indomethacin combined with MK886 is probably due to the peripheral effects of the drugs, since their combination was ineffective against incision-induced allodynia in the contralateral hind paw.

Zileuton (a 5-lipoxygenase inhibitor) or indomethacin slightly reduced the mechanical and thermal hyperalgesia induced in rats by the contact of the nucleus pulposus with the sciatic nerve (33), and inhibited the acetic acid-induced writhes in mice (30). A stronger analgesic effect was obtained when zileuton was combined with indomethacin (33). In contrast, zileuton was ineffective in the tail flick and hot-plate tests (30), thus indicating that leukotrienes have a role in persistent, but not in acute nociception. Dual inhibitors of cyclooxygenase and 5-lipoxygenase, such as licofelone (30), SKF 105809 (33), S-19812 (34), or ketoprofen (13), are effective analgesics in different models of inflammatory or post-incision pain.

The present study demonstrates that preoperative intraplantar administration of drugs leading to inhibition of both the cyclooxygenase and 5-lipoxygenase cascades produces preemptive analgesia in a rat model of incision pain. In contrast, preemptive analgesia is not obtained when only one of these enzymes is inhibited. These results indicate that preemptive analgesia occurs when the local generation of prostaglandins and leukotrienes by surgical incision is pharmacologically reduced. 


\section{References}

1. Woolf CJ. Evidence for a central component of post-injury pain hypersensitivity. Nature 1983; 306: 686-688.

2. Hylden JL, Anton F, Nahin RL. Spinal lamina I projection neurons in the rat: collateral innervation of parabrachial area and thalamus. Neuroscience 1989; 28: 27-37.

3. Dubner R. Neuronal plasticity and pain following peripheral tissue inflammation or nerve injury. Proceedings of the VI World Congress on Pain. Amsterdam: Elsevier; 1991. p 263-276.

4. Woolf CJ. A new strategy for the treatment of inflammatory pain. Prevention or elimination of central sensitization. Drugs 1994; 47 (Suppl 5): 1-9.

5. Woolf CJ, Wall PD. Morphine-sensitive and morphine-insensitive actions of C-fibre input on the rat spinal cord. Neurosci Lett 1986; 64: 221-225.

6. Dickenson AH, Sullivan AF. Evidence for a role of the NMDA receptor in the frequency dependent potentiation of deep rat dorsal horn nociceptive neurones following $C$ fibre stimulation. Neuropharmacology 1987; 26: 1235-1238.

7. Coderre TJ, Vaccarino AL, Melzack R. Central nervous system plasticity in the tonic pain response to subcutaneous formalin injection. Brain Res 1990; 535: 155-158.

8. Dierking GW, Dahl JB, Kanstrup J, Dahl A, Kehlet H. Effect of prevs postoperative inguinal field block on postoperative pain after herniorrhaphy. Br J Anaesth 1992; 68: 344-348.

9. Johansson B, Glise H, Hallerback B, Dalman P, Kristoffersson A. Preoperative local infiltration with ropivacaine for postoperative pain relief after cholecystectomy. Anesth Analg 1994; 78: 210-214.

10. Coderre TJ, Katz J, Vaccarino AL, Melzack R. Contribution of central neuroplasticity to pathological pain: review of clinical and experimental evidence. Pain 1993; 52: 259-285.

11. Woolf CJ, Chong MS. Preemptive analgesia - treating postoperative pain by preventing the establishment of central sensitization. Anesth Analg 1993; 77: 362-379.

12. Dahl JB. Neuronal plasticity and pre-emptive analgesia: implications for the management of postoperative pain. Dan Med Bull 1994; 41: 434-442.

13. Prado WA, Pontes RM. Presurgical ketoprofen, but not morphine, dipyrone, diclofenac or tenoxicam, preempts post-incisional mechanical allodynia in rats. Braz J Med Biol Res 2002; 35: 111-119.

14. Sigurdsson GH, Youssef HA, Owunnwanne A. Effects of two different inhibitors of the arachidonic acid metabolism on platelet sequestration in endotoxic shock. Res Exp Med 1994; 194: 287-295.

15. Rackham A, Ford-Hutchinson AW. Inflammation and pain sensitivity: effects of leukotrienes D4, B4 and prostaglandin E1 in the rat paw. Prostaglandins 1983; 25: 193-203.

16. Levine JD, Lau W, Kwiat G, Goetzl EJ. Leukotriene B4 produces hyperalgesia that is dependent on polymorphonuclear leukocytes. Science 1984; 225: 743-745.

17. Soter NA, Lewis RA, Corey EJ, Austen KF. Local effects of synthetic leukotrienes (LTC4, LTD4, LTE4, and LTB4) in human skin. J Invest Dermatol 1983; 80: 115-119.
18. Tonussi CR, Ferreira SH. Tumour necrosis factor-alpha mediates carrageenin-induced knee-joint incapacitation and also triggers overt nociception in previously inflamed rat knee-joints. Pain 1999; 82: 81-87.

19. Dallob A, Guindon Y, Goldenberg MM. Pharmacological evidence for a role of lipoxygenase products in platelet-activating factor (PAF)induced hyperalgesia. Biochem Pharmacol 1987; 36: 3201-3204.

20. Bennett G, al-Rashed S, Hoult JR, Brain SD. Nerve growth factor induced hyperalgesia in the rat hind paw is dependent on circulating neutrophils. Pain 1998; 77: 315-322.

21. Ge QF, Wei EQ, Zhang WP, Hu X, Huang XJ, Zhang L, et al. Activation of 5-lipoxygenase after oxygen-glucose deprivation is partly mediated via NMDA receptor in rat cortical neurons. $J$ Neurochem 2006; 97: 992-1004.

22. Zimmermann M. Ethical guidelines for investigations of experimental pain in conscious animals. Pain 1983; 16: 109-110.

23. Brennan TJ, Vandermeulen EP, Gebhart GF. Characterization of a rat model of incisional pain. Pain 1996; 64: 493-501.

24. Chaplan SR, Bach FW, Pogrel JW, Chung JM, Yaksh TL. Quantitative assessment of tactile allodynia in the rat paw. J Neurosci Methods 1994; 53: 55-63.

25. Hamalainen MM, Gebhart GF, Brennan TJ. Acute effect of an incision on mechanosensitive afferents in the plantar rat hindpaw. $J$ Neurophysiol 2002; 87: 712-720.

26. Pogatzki EM, Gebhart GF, Brennan TJ. Characterization of A deltaand $\mathrm{C}$-fibers innervating the plantar rat hindpaw one day after an incision. J Neurophysiol 2002; 87: 721-731.

27. Vandermeulen EP, Brennan TJ. Alterations in ascending dorsal horn neurons by a surgical incision in the rat foot. Anesthesiology 2000; 93: 1294-1302.

28. Yamamoto T, Sakashita $Y$, Nozaki-Taguchi N. Anti-allodynic effects of oral COX-2 selective inhibitor on postoperative pain in the rat. Can J Anaesth 2000; 47: 354-360.

29. Whiteside GT, Harrison J, Boulet J, Mark L, Pearson M, Gottshall S, et al. Pharmacological characterisation of a rat model of incisional pain. Br J Pharmacol 2004; 141: 85-91.

30. Singh VP, Patil CS, Kulkarni SK. Differential effect of zileuton, a 5lipoxygenase inhibitor, against nociceptive paradigms in mice and rats. Pharmacol Biochem Behav 2005; 81: 433-439.

31. Kissin I. Preemptive analgesia. Anesthesiology 2000; 93: 11381143.

32. Singh VP, Patil CS, Kulkarni SK. Effect of zileuton in radicular pain induced by herniated nucleus pulposus in rats. Inflammopharmacology 2004; 12: 189-195.

33. Griswold DE, Marshall P, Martin L, Webb EF, Zabko-Potapovich B. Analgetic activity of SK\&F 105809, a dual inhibitor of arachidonic acid metabolism. Agents Actions Suppl 1991; 32: 113-117.

34. Tordjman C, Andre N, Bresson Y, Bellot I, Deschamps C, Pastoureau $P$, et al. General pharmacology of the butanamide derivative $S$ 19812, a new dual inhibitor of cyclooxygenase and lipoxygenase pathways. Arzneimittelforschung 2003; 53: 844-849. 